\title{
8
}

\section{NO ONE SHOULD ACCEPT A MISERABLE LIFE LIKE THAT!'}

\section{Exploring the drivers of and entrypoints for reducing violence against adolescent refugees in Gaza}

\section{Bassam Abu Hamad}

\section{Introduction}

While violence affects all communities around the world, certain contexts and categories of people are at greater risk than others (World Health Organization (WHO), 2002). The United Nations Children's Fund (UNICEF) defines violence as 'all forms of physical or mental violence, injury or abuse, neglect or negligent treatment, maltreatment or exploitation, including sexual abuse' (UNICEF, 2017). Adolescence is a unique developmental life stage during which young people especially in conflict-affected areas - are at heightened risk of violence and victimisation. In congruence with the UNICEF definition of violence, the Gender and Adolescence: Global Evidence (GAGE) research programme includes bodily integrity as one of six key capability domains, focusing on adolescents' freedom from violence and protection from gender-based violence (GBV), including child marriage, harmful traditional practices and other forms of coercion (GAGE consortium, 2019).Violence can harm adolescents in the short and long term and can result in injury, death, psychosocial harm, maldevelopment and deprivation across the life course (WHO, 2013). In conflict-affected contexts, in particular, adolescent boys and girls are at greater risk of exposure to various forms of violence, including conflict-related violence, domestic violence, physical and psychological violence, and sexual violence (Samuels et al., 2018).

While none of the Millennium Development Goal (MDG) targets or indicators explicitly addressed violence, their successors, the Sustainable Development Goals (SDGs), do incorporate targets on violence (Butchart, 2020). There are at least four SDG targets ${ }^{1}$ related to violence and seven SDGs with targets that address risk factors for violence. ${ }^{2}$ However, despite the international commitment to achieving the SDGs by 2030, the prevailing political and economic context in Palestine is not conducive to realising these global commitments. 
Driven by the politics of the Israeli occupation and concerns about its implications for the ongoing Palestinian-Israeli conflict, the available literature on violence in Palestine mainly focuses on political violence and on men and older male adolescents; girls are largely 'invisible' (Thabet et al., 2004) and almost absent from policy frameworks. In Gaza, adolescents, especially girls, are typically subsumed into the categories of children or youth, and their challenges and needs are lumped together with those of their families, siblings or mothers. Adolescents (particularly girls) are largely perceived as passive recipients of aid and rarely included in research or programming, most of which adopts a top-down approach (Tefferi, 2010), which further increases their marginalisation. This chapter addresses the challenges and opportunities facing Palestinian adolescent stateless refugees in preserving their bodily integrity in Gaza, a context characterised by long-term political turbulence, strict conservative norms, economic collapse and over-reliance on short-term humanitarian aid (Samuels et al., 2018).

While the Global Compact on Refugees (UNHCR, 2019) does not explicitly tackle violence, it could contribute to the violence prevention agenda, such as initiatives around safe return for displaced persons, peacebuilding, and relief and welfare programmes for refugees. The SDGs also provide a potentially powerful violence prevention agenda by addressing risk factors for violence such as social protection and poverty reduction, ending discrimination against girls and women, promoting early childhood development, and reinforcing the rule of law and justice for all. Although international commitments to ending violence are gaining traction, there is still a limited understanding of how best to achieve this in practice in stateless, protracted conflict-affected contexts like Gaza, in which adolescents face multifaceted challenges that constrain their development trajectories.

This chapter explores types and risk factors of violence among different groups of adolescents (girls, boys, younger, older) at different levels (individual, household, community) and the availability of services (including service providers' attitudes and behaviours towards adolescents). Additionally, we discuss how humanitarian programmes can be adapted to address the longer-term impacts of displacement that go beyond urgent basic needs. We aim to contribute to the debate about how formal and informal support can be more effective in preventing or ending violence, including providing insights into the role of development actors in protecting adolescents' bodily integrity.

\section{Context}

Gaza is a narrow strip of land (45 kilometres long) between Israel, Egypt and the Mediterranean Sea, home to around 2 million people, making it one of the world's most densely populated areas (see Table 8.1). Once a thriving centre of culture, economy, education and tourism, over the past 75 years, Gaza has witnessed a cycle of military incursions by Israel and violent uprisings (intifadas) by Palestinians. The never-ending battle for statehood, exacerbated by the Israeli blockade, and the struggle for subsistence are thus the main preoccupations of Gaza's inhabitants, 66 
per cent of whom are refugees (Palestinian Central Bureau of Statistics (PCBS), 2018). Most were forcibly displaced from their original villages and cities following the Arab-Israeli conflict of 1948. The State of Palestine is regarded as a Nonmember Observer State at the United Nations (UN).

Expropriation of land has created a condition of dispossession that has further compromised Palestinians' abilities to withstand the deliberate de-development strategy pursued by Israel, through punitive economic and military policies. Israel still has overall sovereignty of Gaza, controlling its borders, economy, movement of goods and people, electricity, communications and security - the key aspects of Palestinians' lives. In Gaza, nearly 42 per cent of refugees live in one of eight camps operated by the United Nations Relief and Works Agency for Palestine Refugees in the Near East (UNRWA) (PCBS, 2018). A combination of national, social, legal, economic and political factors explain the persistence of the refugee camps after more than seven decades.

Since 1948, the Palestinian people have experienced many clashes with Israel, including three recent consecutive wars on Gaza (2008/2009, 2012 and 2014) and multiple confrontations between Israeli forces and Palestinian fighters. These conflicts have all contributed to loss of life, land and livelihoods, driving further displacement. This has weakened social networks, increased incidence of psychological and emotional difficulties, and exacerbated poor housing and sanitation. It has also led to high poverty levels (more than 60 per cent of Gazans are poor or extremely poor) and high unemployment rates (around 70 per cent among youth and women). According to the World Bank, the war in 2014 alone resulted in the destruction of 160,000 homes, displacing more than 500,000 Gazan residents (World Bank, 2015). The UN has predicted that Gaza may be uninhabitable by 2020. It has described the situation as a 'protracted human dignity crisis' and considers it as a 'collective punishment' in clear violation of international humanitarian law (UN, 2017).

Adolescents in Gaza are regularly confronted with violent experiences as a result of the ongoing conflict, including physical injury and even death, but no specific data on this discrete age category is available. A report from the Ministry of Health (2020) indicates that over the past six years, more than 700 children and 500 women were killed and around 17,000 were injured or left permanently disabled.

Internecine violence between Hamas and Fatah in 2006 and 2007, and the subsequent takeover of Gaza by Hamas, has resulted in imposing the blockade and international sanctions on Gaza since 2007 till now, which have further contributed to vulnerabilities of the population. Hamas's dominant Palestinian Legislative Council (PLC), the legislature of the Palestinian inhabitants of the Occupied Territories, has been unable to meet officially since 2007 . This has affected policy and law-making processes. Palestine's legal framework is not only outdated but also highly unequal from an age and gender perspective. Of 140 laws issued by Presidential Decree (because of the paralysis of the PLC) between 2007 and 2015, only 2 per cent were related to women's rights. None had a clear impact in addressing violence and discrimination against women and girls (Human Rights Council, 2017).

Table 8.1 shows the key demographic characteristics of Gaza. 
TABLE 8.1 Key demographic characteristics of Gaza

\begin{tabular}{|c|c|c|c|}
\hline Variable & Value & Variable & Value \\
\hline Total population & 2 million & Population density & 5,500 per sq $\mathrm{km}$ \\
\hline Average household size & 5.7 & Total fertility rate per woman & 4 children \\
\hline Adolescent proportion & $22 \%$ & $\begin{array}{l}\text { Gross domestic product } \\
(\text { GDP) per capita }\end{array}$ & $\$ 1,000$ \\
\hline $\begin{array}{l}\text { Adolescent fertility } \\
\text { rate }\end{array}$ & $\begin{array}{l}66 \text { per } \\
1,000\end{array}$ & $\begin{array}{l}\text { Women's participation in } \\
\text { workforce }\end{array}$ & 19 \\
\hline $\begin{array}{l}\text { Population density in } \\
\text { camps }\end{array}$ & 50,000 & Adult literacy rate & $96.4 \%$ \\
\hline $\begin{array}{l}\text { Proportion of } \\
\text { population who are } \\
\text { refugees }\end{array}$ & $66 \%$ & Youth bulge & $30 \%$ \\
\hline Poverty rate & $60 \%$ & Relying on food assistance & $80 \%$ \\
\hline Unemployment rate & $50 \%$ & $\begin{array}{l}\text { Receiving social assistance } \\
\text { from Ministry of Social } \\
\text { Development }\end{array}$ & 75,000 \\
\hline Food insecurity & $55 \%$ & $\begin{array}{l}\text { Receiving assistance from } \\
\text { UNRWA }\end{array}$ & 22,000 \\
\hline $\begin{array}{l}\text { Females' median age of } \\
\text { marriage }\end{array}$ & 19 years & $\begin{array}{l}\text { Desire to migrate among } \\
\text { youth }\end{array}$ & $37 \%$ \\
\hline $\begin{array}{l}\text { Proportion of } \\
\text { population with a } \\
\text { disability }\end{array}$ & $8 \%$ & $\begin{array}{l}\text { Municipality water suitable } \\
\text { for drinking }\end{array}$ & $3 \%$ \\
\hline
\end{tabular}

Sources: PCBS, 2015; PCBS, 2019a; UNICEF, 2014a;World Bank, 2019.

\section{Literature review}

Although the right of all girls and boys to protection from all forms of violence has been enshrined in international human rights treaties, particularly the UN Convention on the Rights of the Child (UNCRC), violence perpetrated against children remains widespread, especially in conflict-affected areas (UNICEF, 2017). Abuse has serious physical, mental, social and economic consequences in the short and long term (UNICEF, 2014b), which can result in maldevelopment and deprivation across the life course, making adolescents who experience violence more likely to be left behind. A meta-analysis study in 2016 estimated that more than three-quarters of the world's children had experienced moderate or severe physical, sexual and/or emotional abuse during the past year (UNICEF, 2017). There is a dearth of evidence about domestic violence and violence originating from cultural norms among older adolescents (15-19 years), especially in relation to gendered practices, as older adolescents are not usually included in Multiple Indicator Cluster Surveys (MICS) (UNICEF, 2014b). Therefore, the evidence based on prevalence, risk factors, experiences of older adolescents (particularly girls) and those living in conflict-affected areas remains very limited (UNICEF, 2018). 
With regard to types of violence, UNICEF estimates that globally, 60 per cent of children (up to 14 years) have experienced regular physical punishment by caregivers (UNICEF, 2014b), 70 per cent have experienced psychological aggression in the past month and 10 per cent of girls have experienced sexual violence. Despite under-reporting, evidence suggests that nearly one-third (29 per cent) of females have experienced physical and/or sexual violence perpetrated by their partner (WHO, 2013). Evidence shows that between 20 per cent and 50 per cent of girls and boys experienced different kinds of violence in and around schools in the past year (UNESCO, 2017).

\section{Violence in conflict-affected contexts}

In contexts characterised by protracted conflict and displacement, adolescent boys and girls are more vulnerable to abuse, exploitation, violence and harmful practices such as child marriage (Women's Refugee Commission, 2016). They face distinct and overlapping risks and vulnerabilities, though they are largely not prioritised for support. Research about violence other than political and sexual violence associated with armed conflict is limited. However, a GAGE survey with adolescents in Jordan (predominantly refugees) shows that 49 per cent had experienced violence at home (Jones et al., 2019). The same source indicates that nearly 58 per cent of adolescent boys (compared to 25 per cent of girls) reported having experienced corporal punishment at school, and there are also high levels of peer violence (46 per cent for boys, 38 per cent for girls). Adolescents in conflict and stateless situations may also be directly exposed to political or other violence, even witnessing their parents being abused and/or abducted (Samuels et al., 2018).

In 2011, a PCBS violence survey indicated that 95 per cent of households in Gaza reported ever being directly exposed to political violence from the Israeli occupation and 64 per cent of households were exposed to economic violence (PCBS, 2011); data on adolescents' experiences of violence is not available. In 2014, during the acute stage of Israeli military operations, 28 per cent of the population were internally displaced, staying in UNRWA schools designated as emergency shelters (Samuels et al., 2018). At these centres, girls, in particular, were exposed to different kinds of violence, in addition to overcrowding, lack of privacy, inadequate sanitation and hygiene, insufficient access to water and lack of electricity, as well as further bombardments by Israel.

\section{Violence takes different forms in Gaza}

The PCBS's most recent survey on violence (2019b) shows that more than onethird of married women had experienced violence by their husband in the past year, and the prevalence of violence against non-married youth by household members was even higher. There is no data specifically about adolescents' experiences, but the PCBS MICS study (2015) reveals that Gazan parents almost universally use corporal punishment against their children. Although boys more commonly experience 
physical abuse, girls either experience or witness physical and psychological aggression that creates expectations about their own prospects as adult women. The use of corporal discipline was more common among the poorest quintile, camp residents, parents with lower education and male respondents (PCBS, 2015). As they become older, adolescents' exposure to violence decreases, though still more than half (56 per cent) of adolescents aged 12-17 had experienced violence from caregivers in the past year (PCBS, 2019b). The same survey shows that nearly half of boys aged 12-17 and 17 per cent of girls the same age reported experiencing some form of violence at school.

\section{Conceptual framing}

Exploring the lived experiences of vulnerable, stateless adolescents and telling their untold stories is vital if the 2030 Agenda for Sustainable Development's call to leave no one behind is to be realised (UNDP, 2018). This chapter focuses on bodily integrity and the age- and gender-related vulnerabilities of adolescents in the context of a political turbulence. It recognises the need to avoid depoliticising adolescent agency and better connect the contextualised knowledge and personal experiences of younger people to broader processes of social (in)justice or inequalities' (Cahill and Hart, 2006; Ansell, 2009).

This research, part of the GAGE longitudinal study, uses the ' 3 Cs' conceptual framework - capabilities, contexts and change strategies - to explore what works to support adolescents in developing their capabilities across six key domains, of which bodily integrity and freedom from violence is one (GAGE consortium, 2019). GAGE's focus on capabilities draws on Amartya Sen's work (1984, 2004) and reflects commitments to a holistic understanding of young people's rights and the need for investment across all areas of their lives, as enshrined in the UNCRC. Sen's capabilities approach proposes that in order to achieve and do things that they value, individuals need assets such as knowledge, skills, bodily autonomy and voice, among others (Sen, 2004).

By focusing on under-researched and stateless vulnerable Palestinian adolescents, who face multiple and interlinked vulnerabilities, the research contributes to a better understanding of how to protect this at-risk group from violence, which manifests in multiple ways as a result of structural injustice that cascades down from the occupier to the community institutions and families. Being a stateless refugee, displaced, living in a war-like context for much of their young life, can make young people particularly vulnerable to violence and related deprivations, which also intersect with and reinforce other vulnerabilities such as psychosocial and health risks throughout the life course (UNICEF, 2018; GAGE consortium, 2019).

GAGE's approach uses an ecological model to understand adolescents' vulnerabilities, taking account of the culturally and socially constructed micro- and macro-level factors that interact to shape adolescents' experiences. The conceptual framework emphasises the role of context in shaping the opportunities for and threats to young people to scale up their capabilities. In line with an anthropological 
approach, context includes not only the individual-level factors and relationships in which young people are embedded at the household or family level but also the community-level factors that help shape social norms around gender and age, and the larger political and economic environmental factors that underpin drivers and responses to violence.

We use an ecological frame to conceptualise violence, exploring risks at the macro, meso and micro levels facing Palestinian stateless adolescent refugees in preserving their bodily integrity. Macro-level risk factors include long-term statelessness, displacement, political turbulence, ongoing conflict, economic collapse, dedevelopment and militarisation. Meso-level factors include strict conservative social norms, cultural norms around parenting practices, age and gender hierarchies, lack of age- and gender-sensitive legislation, outdated legal frameworks, lack of social protection services, discriminatory laws and an inaccessible justice system. Microlevel risk factors include household poverty, harsh parenting practices, household stress and conflict and the generalised acceptability of violence and discrimination (UNICEF, 2016).

Finally, the GAGE conceptual framework attends to change strategies - the policies and programming needed to support adolescents' bodily integrity, which must account for the contextual realities of their lives and the prevailing risk factors. This underlines the importance of connecting the experiences and voices of adolescents to concrete recommendations about what actions can be taken to address the intersecting vulnerabilities highlighted.

\section{Methodology}

This chapter draws on participatory mixed-methods research conducted in Gaza in 2017. We carried out a service-mapping exercise with 70 service providers (based on key informant interviews) and 107 adolescents (using an interactive, tablet-based QuickTapSurvey ${ }^{\mathrm{TM}}$ module), complemented by qualitative research with adolescents, their peers and families. This included 12 focus group discussions (FGDs) using vignettes, object-based interviews and social network mapping, as well as 35 in-depth interviews (IDIs) (see Jones et al., 2017). We also drew on findings from our 2016 participatory action research project in Khanyounis, Gaza, involving 35 adolescents aged 15-19, who undertook research that included peer interviews, participatory photography and videography. We conducted secondary analysis of the relevant national datasets, especially data collected by PCBS.

We used purposive sampling to ensure a good mix of participants from different socioeconomic backgrounds, including in-school and school dropouts, adolescent mothers, adolescents directly affected by the conflict, orphans, child brides, those engaging in child labour, divorced or separated adolescents and adolescents with disabilities. Research was conducted in three diverse localities: Jabalia refugee camp, Shajaia and Khanyounis. 


\section{Data analysis}

After translation, all interview transcripts were thematically coded and analysed. To facilitate the coding process, in-depth debriefings were held to discuss emerging findings and key themes. Subsequently, the transcripts were coded using MAXQDA 12 software; findings were first aggregated by instrument, then collectively across all instruments.

\section{Key findings and analysis}

\section{Magnitude of violence and its risk factors}

Our findings indicate that Gaza is a hostile environment for adolescents in general, and particularly for girls. Adolescents face compounded and interlinked vulnerabilities that trigger their exposure to different types of violence. Adolescents' exposure to violence in Gaza is very much driven by the long-term political turbulence, the protracted Israeli occupation and blockade, military attacks, lack of physical safety, lack of safe places or shelters, displacement, destruction of livelihood assets and Palestinian political divisions. A 14-year-old girl in Jabalia camp, whose father died in 2014 (during the war), said during an in-depth interview:

Two things worry me: the night and the war. I worry about everyone in my family, I don't want them to leave the house. I like to sleep before everyone, I hate staying at night alone.

Our findings show that adolescents are overwhelmed by their exposure to violent experiences. Fear of further outbreaks of fighting or war were reported as key threats, especially among those who had witnessed earlier periods of consecutive hostilities. One younger girl in an FGD in Jabalia camp described her fears:

Since the last conflict in Gaza, I scream when I hear bombing. I feel frightened to go to the toilet alone. Also, if my family members leave me alone, I start screaming.

A 15-year-old girl with a disability from Shajaia, who evacuated her house with her family during the war, ranked war as her biggest fear: 'When war occurs, no one knows what will happen.' Older adolescent boys were less explicit in expressing their fears but mentioned insecurity as a threat to all citizens. Adolescents who suffered physical injuries during previous wars could not name any other worry, indicating the psychological as well as physical scars they bear. A 19-year-old girl with a disability, in Jabalia camp, said:

My hand was hit in the last conflict when I was playing with the other kids and the Israelis bombed our neighbour's house. A big stone fell on my hand 
and it was broken. I have never received any psychological support after what happened.

During the acute stage of military operations, many adolescents and their families (28 per cent of the entire population in the 2014 operation) were internally displaced, staying in UNRWA schools designated as emergency shelters. At these centres, girls in particular were exposed to different kinds of violence, compounding other problems such as overcrowding, lack of privacy, inadequate sanitation and hygiene, insufficient access to water and lack of electricity (see Box 8.1).

\section{BOX 8.1 VIOLENCE EXPERIENCED BY GIRLS IN TEMPORARY SHELTERS}

In a focus group discussion, older girls from Shajaia who lost their homes due to the Israeli bombardment in 2014 described their experiences during and after the war:

We spent a whole year in the UNRWA school. ... It was a tough time and was hard to go to the bathroom freely, the place was very crowded, very dirty, and a total lack of privacy. Our families prevented us from going alone to the bathroom at night because the school was full of men. They were afraid that any of us would be raped, which already happened in one of the shelters. ... Three male relatives accompanied us for protection.

Once I had my period at night when everyone was asleep. [There was] no one to come with me to the toilet so I had to ask my sister to hold a blanket to give me some privacy to put in a pad till the morning.

We faced a lot of difficulties every time we need to have a bath in the shelter. We did not use the bathroom. We bathed in the same room we used to sleep in after we asked all the families who shared the room to leave. Sometimes there were two or four families sharing the same room and all of them had to get out if any of us needed a bath.

Source: Participant in focus group discussion with older girls, Shajaia.

Our findings confirm that adolescents have not been protected from the effects of the ongoing conflict, and their parents have focused on ensuring their survival, ignoring other needs. Another consequence of the political violence is that many adolescents have assumed new (adult) responsibilities, in cases where the family breadwinner has died suddenly. In 2014, a new category of household emerged in Gaza - child-headed households (Abu Hamad et al., 2015). 
During the FGDs and IDIs, when adolescents were asked about being directly exposed to violence, all reported experiencing different types of violence within their household, neighbourhood, school and community. Most mentioned physical, verbal and political violence perpetrated by fathers, uncles, teachers and by Israeli forces; they also mentioned fights between siblings. In a focus group discussion, a 15-year-old boy said: 'Our house is full of hate; it is extremely difficult.' The protracted nature of the conflict, with no end in sight, led adolescents to feel frustrated and anxious about their current and future situation, with one girl in an FGD in Jabalia camp commenting: 'I don't think there will be a future for us. I am desperate about the whole life. I want to commit suicide - it's better than this life.'

It is important to note that interpersonal violence is mediated by poverty, unemployment and economic hardship resulting from Israeli de-development policies - which can manifest in adolescents' exposure to domestic violence. Fathers sometimes push their children to work in dangerous jobs and push girls to marry as children (Pereznieto et al., 2014; Abu Hamad et al., 2014). A 17-year-old girl in Shajaia summed up adolescents' life experience in Gaza by stating:

Our situation is tough and making life very challenging for everyone in the Gaza Strip, no one cares about our basic livelihood needs.

Exacerbated by the blockade and ongoing conflict, studies show that conservative discriminatory norms create additional problems for girls, including child marriage, restrictions on their movement, overprotection, pressures linked to 'family honour' and sexual harassment (Samuels et al., 2017). Whilst these measures are undertaken by families with the aim of keeping girls safe in the volatile environment described by young people previously, they are often experienced as restrictive and frustrating by girls who wish to be able to participate in their communities and exercise agency over their mobility. Moreover, strict age hierarchies leave little room for younger generations to participate in family decisions (PCBS, 2016). Some girls reported having to stay at home in preparation for marriage or for other reasons decided by their fathers. As one older girl from Jabalia said: 'They sacrifice their daughters' mental health only because they worry about people gossiping.' Sexual harassment worries girls even if they have not experienced it directly. Stories they hear influence them in different ways (Abu Hamad et al., 2017).

Our findings also suggest that violence in Gaza is gendered. Boys are more exposed to physical violence from the ongoing conflict as well as at household, school and community levels, and at greater risk of child labour, while girls (especially older girls) are more exposed to psychological violence due to severe restrictions on their movement and socialising, for fears that include girls' jeopardising family honour, but are also linked to concerns about their safety given insecurity in the wider community. 


\section{Which adolescents are at greater risk of violence?}

Some groups of adolescents are at greater risk of violence, including those from poor families, adolescents who lost a family member (especially the breadwinner) and/or their homes and livelihood resources as a result of the conflict, those living in areas with strict conservative norms and those in marginalised or border areas. Other groups include adolescents with disabilities (especially older girls), adolescents with limited education, boys who dropped out of school and are working and girls who dropped out of school and are homebound. Those at greatest risk include orphaned children, early-married adolescents and adolescent mothers, divorced adolescents and adolescents living in extended families.

\section{Domestic violence}

During our qualitative research, many of the adolescents we interviewed in Gaza reflected on the strong influence their parents have on their lives. Whilst many adolescents felt that their parents were supportive, others expressed that they were subject to restrictive measures. Almost all reported experiencing verbal and physical violence by a household member, particularly fathers. One girl expressed her confusion at the dissonance between her father's concerns to protect her and his use of corporal discipline:

I cannot understand my father, while he always says that I am his dear and I am 'redline' [untouchable] so no one can hurt me, he himself beats me.

Others reported maltreatment of and by siblings, as a younger girl in Shajaia noted:

My younger sibling treats me badly. My mother hits him.

Adolescent girls expressed being affected by witnessing violence against their mothers. During an IDI, one participant said:

I watch my father beating my mother. I feel helpless and worthless.

Boys believe they are more often subjected to violence than girls, with one noting, 'Girls are dearer to parents.' While girls are more likely to experience verbal than physical violence, a 12-year-old girl in Shajaia said: 'Verbal violence and discrimination also result in psychological stress'. Adolescents' exposure to domestic violence is further complicated by their exposure to violence in public places, as explained in the subsequent section about violence at school. A 16-year-old boy who dropped out of school said:

I decided to stop schooling, I was frequently beaten whenever I make wrong answers. One day I was fed up and decided to stop. A few days later, my father 
got to know about it and beat me badly to return to school. I was beaten anyway so I ignored him.

Older girls who had permanently dropped out of school suffered more than their peers in school, as one commented:

Those at schools are much better. We are more deprived, isolated and do a lot of housekeeping.

Box 8.2 illustrates the vulnerabilities facing girls who have dropped out of school.

\section{BOX 8.2 MULTILAYERED VIOLENCE}

'I am Wafa, an 18-year-old girl, from Khanyounis. I live with my extended family in a very large house with only two rooms!'

The house is overcrowded and unhealthy. Forced to leave school after eighth grade to look after her younger siblings, Wafa spends her days trapped inside, 'looking through windows with a lot of anger, sorrow and sadness inside me'. When her family decided she would leave school to care for her divorced sister's four-year-old son, Wafa understood that she was being asked to sacrifice her future. Wafa's life - at least until the past few weeks - has been 'miserable' as it has revolved around nothing other than the 'work in the household'. She is 'tired all the time', as she is juggling a large workload on little sleep. She is frustrated that her brothers do nothing other than 'sitting in the house', but when she complains and refuses to prepare the Narjela [hookah/hubbly-bubbly], her brother 'hits her hard with his belt'. As she is not allowed outside without permission, there is little way for her to escape.

Wafa has mixed feelings about her mother. On the one hand, she is very proud of her, as she works hard to keep her family fed and clothed even in the absence of support from her husband. On the other hand, Wafa 'doesn't want to be like her'. She feels that no one should accept so 'miserable a life'.

Source: Interview with 18-year-old female dropout, Khanyounis.

Domestic violence is multifaceted and may include depriving adolescents of their right to access medical care, especially among poorer families, who face difficult decisions over how to spend tight household budgets. A 12 year old girl with a disability in Shajaia explained: 
My parents would argue sometimes about the medicine cost and my dad would kick my mother outside the house. Sometimes he would say that he does not care what happens to me, saying 'may she die'!

Because gendered norms see girls' virginity as central to family honour, girls' and young women's access to non-maternity-related care is largely precluded (The Palestinian Initiative for the Promotion of Global Dialogue and Democracy (MIFTAH) et al., 2015). Parents often do not allow unmarried girls to visit a gynaecologist because they are concerned that any invasive procedure might lead to loss of the hymen. One older girl in an FGD in Shajaia said:

Fathers will prevent girls from visiting a doctor no matter how severe the condition because they believe there is a chance that her virginity will be ruined, and as a result she will not get married.

Adolescents reported that the male head of household typically makes decisions that affect their lives. Indeed, intergenerational conflict was obvious between adolescents and their parents, who seldom consider their adolescent children's unique needs and perspectives. Many boys mentioned that they rebel against fathers' authority and leave their homes because of clashes with parents, but girls tend to react more passively, internalising their problems. Adolescent girls (in a decision-making table exercise with 16-19-year-olds in Khanyounis) indicated that their mothers often decide how they spend their time: 'When I don't finish my homework, my mom shouts "stand up and get to [house] work".

Instead of being supported to transition safely through adolescence, puberty adds further restrictions on girls' lives. Adolescents who participated in the research felt that their families restrict their daughters' movements at the onset of puberty, stopping them playing outside the house, preventing them going outside alone especially after sunset, reducing contact with male cousins and insisting they wear the hijab.

\section{Violence at school}

Our findings show that although girls enjoy going to school, conservative norms and worries around family honour worry them. As a 19-year-old girl from Jabalia camp indicated:

When I used to go to school, my dad would stand on the street and prohibit us from walking with friends. Our school was far, so he would make my brother walk us to school.

Another threat reported by adolescent girls were boys and men on the streets (vendors, taxi drivers) that 'annoy and harass girls' when they are on their way to school. This appeared to happen more often to older girls. Even being looked at by a man 
can cause parents to withdraw their daughter from school, as one older girl in an FGD in Jabalia camp explained:

I talked to my school counsellor about the problems I faced by boys who used to throw messages [that] were written on papers and some students called me 'lover girl'. When I told my mother about those boys, she got angry and prevented me from going back to school. Then I got married directly after I dropped out.

Some teachers were reported to have resorted to punitive disciplinary measures. Almost all adolescents mentioned experiencing violence (physical and verbal) in schools and threats to have their grades lowered (see Box 8.3). Moreover, girls pointed out that teachers do not show any understanding of their needs during menstruation and sometimes do things to hurt them psychologically. For example, participants from Shajaia mentioned that they are rarely excused from exams during menstruation and are not allowed to rest or leave school to go home if they are experiencing menstrual pains, except in rare cases.

Others mentioned violence perpetrated by students as a critical concern, as illustrated by one younger girl from Shajaia:

My classmates treat me badly. There was that one time when a classmate pushed me against the wall, and I told her 'May Allah forgive you'.

Participants with disabilities also indicated that violence and bullying in school caused them to drop out. Their responses also indicate that the school environment is not adolescent-friendly, complaining of overcrowding and inadequate and dirty toilets, as one girl in an FGD in Shajaia commented: 'the smell is intolerable.'This was particularly challenging for girls during their menstrual cycle. In many schools, sport classes for girls are cancelled and replaced either with regular classes or by cleaning the classrooms and toilets! One girl in an FGD for older girls in Shajaia explained:

During sport class, we do not play or practice. Instead, we are handed sweepers to clean the place.

\section{Violence from healthcare providers}

Our findings confirm that schools are not the only places that are unwelcoming for adolescents. There are limited health services available, and existing services are often not adolescent-friendly, with many adolescents reporting exposure to violence when seeking services. In an FGD with older girls in Jabalia, an 18-year-old noted:

I went to the hospital where I spent three days crying without any good healthcare. The rooms were unclean and blood all over. The curtains were dirty too. The smell was very awful too. 


\section{BOX 8.3 VIOLENCE IN SCHOOLS}

Adolescents reported mixed experiences about their treatment by teachers and staff at school. While some noted that they had supportive and caring teachers, others underscored that they have been subjected to physical, psychosocial and verbal violence by teachers, administrative staff and students. Physical violence by teachers and the school director was common, as these quotes from in-depth interviews (IDI) or focus group discussions (FGD) show:

One day a teacher came suddenly and started to hit a student without a reason.

(Boy, FGD with older adolescents, Shajaia)

The headteacher grabbed my ear and slammed me twice on my ear. My ear kept hurting for two weeks.

(IDI with 16-year-old boy, Jabalia camp)

The teacher made us carry around a banner with 'I am donkey' on it.

(FGD with older girls, Jabalia camp)

A counsellor always has a stick to beat us with.

(FGD with older adolescent boys, Shajaia)

If a student is absent from the school for family reasons, the school administration would punish her by asking her to stand up under the sun in the schoolyard for one or even four classes without eating or drinking water.

(FGD with older adolescent girls, Jabalia camp)

Many adolescents had also been threatened with having their grades lowered.

Some mentioned retaliating against teacher violence:

One day the teacher asked my older brother to read something on the board but my brother couldn't. The teacher hit him hard on his hands, head and legs. My two older brothers came to school and broke the chairs on top of all the teachers because one of them hit my brother. It is true that my brother couldn't read, but that does not give the teacher the right to hit him like a sheep. He could've struck him once or twice and that's it, but to beat him on his head, hands and legs, no, it's not right.

(IDI with 12-year-old boy, Shajaia) 
Adolescents were critical of health staff who were often insensitive to their needs. One younger girl in an FGD in Jabalia camp said:

I was so afraid when I went to the dentist in a clinic. The dentist shouted at me and said 'if you don't want to be cured, go home!' Then I went home without checking my teeth.

One participant in an FGD with younger boys in Shajaia explained:

We don't like hospitals because the staff there do not like to help, they yell at us, and tend to ignore us.

Married and pregnant adolescent girls also reported some negative encounters with healthcare providers during childbirth, including experiencing a lack of privacy during treatment and being made to feel very unsafe, emphasizing a dearth of adolescent-friendly services.

\section{Discussion}

Due to the prevailing protracted humanitarian context, violence in Gaza remains widespread, endemic, institutionalised and normalised, yet there are few support services for children and adolescents who have experienced violence (PCBS, 2011, 2019b). Our findings confirm that adolescents experience violence everywhere at home, in their neighbourhood, in schools and healthcare institutions, on the streets and other places. Perpetrators are wide-ranging and include Israeli forces, parents, intimate partners, members of the extended family, teachers, healthcare workers and peers. From a wider anthropological perspective, risk factors at the macro, meso and micro levels intersect and predispose adolescents to different types of violence at different places.

Because domestic violence against children and women is culturally regarded as a private family matter, less than 2 per cent of abused women and young people seek legal support (PCBS, 2019b). This percentage has not changed over the past decade, raising important questions about the effectiveness of strategies implemented to control violence. Although less evident in the quotes above, findings from our larger study indicate that family members, despite demanding girls' submissiveness, also act as sources of support (Samuels et al., 2018). In one of the research tools (the social support quadrant exercise), mothers, sisters, aunts, uncles (and, less frequently, brothers and fathers) were mentioned as the people who provide support for adolescents experiencing violence. Other categories (including school counsellors, service providers, police and legal counsellors) were regarded as less supportive. Unpacking the situations in which this support is provided may help to suggest strategies to control violence.

During our service mapping exercise, none of the facilities visited reported working exclusively or solely with adolescents to control violence; they tended to 
focus on younger children or youth. Also, less attention has been paid to domestic or school-based violence. Where programmes did exist, they tended to be neither age- nor gender-sensitive and failed to address adolescent girls' needs for protection. Moreover, most organisations focus on awareness-raising for youth and providing legal support for married women, while very few address the root causes of violence, given the intractability of the continued Israeli occupation. Our mapping exercise shows that most interventions to control violence are short term, donordriven, not well-coordinated, not sustainable and do not tackle violence in a comprehensive way. Few non-governmental organisations (NGOs) provide specialised violence-related support. Other challenges hampering proactive targeting include lack of data and rigorous surveillance about violence and services for those who have experienced violence (UNDP, 2018).

The Ministry of Women's Affairs had adopted a cross-sectoral National Strategy to Combat Violence Against Women 2011-2019 (Ministry of Women's Affairs, 2011), but like most strategies in Palestine, it has not been translated into practical polices on the ground. Because of political and economic uncertainty, lack of Palestinian sovereignty and control over resources, strategies are usually not budgeted and mostly rely on unreliable short-term donor aid. Because violence has been part of people's everyday experiences in Gaza for so long, it has become a norm transmitted across generations. The literature indicates that when violence is pervasive and sustained, social norms change (Al-Krenawi, 2012) and violence becomes "normal' in the community. The ongoing conflict with Israel also increases militarisation of Palestinian youth and men and increases adoption of inappropriate masculinities in the community as a way to claim power, equating violence with voice and agency (Hart, 2010). Indeed, in such contexts, violence is used as a conflict resolution mechanism by the perpetrators (Jewkes, 2002).

The social constructed norms around gender equality and the acceptability of violence and discrimination have played an important role in increasing violence in Gaza. Parents, who are extremely distressed by depletion of their economic and emotional resources and the ongoing insecurity, use violence as an outlet, with children (particularly girls) often the target (Müller and Tranchant, 2017). In Gaza, child-parent relations are regarded as a private, family issue that should remain within the household. Cultural norms dictate that children accept and tolerate all parents' behaviours even if they do not agree with them.

On the positive side, the School Mediation Programme implemented by the Gaza Community Mental Health Programme is an example of good practice to combat violence. However, this initiative still requires scaling up and further enhancement by complementary services, especially referral pathways as appropriate to specialised centres. Aisha Association implements a comprehensive programme targeting victims of GBV and is another example of good practices, though it mainly targets married women. It provides training, awareness, legal and family counselling, and vocational training and supports individuals to set up microcredit projects - in a package that usually lasts for one year for each survivor. The Democracy and Conflict Resolution Centre coordinates two-child protection networks established by the Ministry of Social Development in coordination with relevant sectors. The 
Centre targets children with severe vulnerabilities such as those engaged in criminal acts, child labour, street children and adolescents who practice begging, but it is unlikely to deal with domestic violence except in extreme cases.

\section{Conclusion and policy implications}

\section{Conclusions}

This chapter highlighted the different forms of violence perpetrated against adolescent boys and girls in Gaza, resulting from the interplay of risk factors at the macro, meso and micro levels of political context, community and the individual/household. Unlike other studies of political violence that usually focus on males and adults, this research focused on age and gender-specific challenges facing adolescents to protect their bodily integrity. The chapter has analysed the structural, social and contextual root causes of violence and shown the ways that these are interconnected. Families' experiences of insecurity and anxieties over their daughters' safety in particular lead them to take restrictive, punitive and often physical approaches towards their adolescent children, with these measures socially sanctioned by norms about family honour and respectability. Violence amongst peers and in schools is also largely overlooked, despite having a clear impact on adolescent wellbeing.

This chapter has also shown where there are currently gaps in support for adolescents. Palestine has acceded to some of the key human rights conventions related to women and children, and the SDGs (with the obligation to eliminate all forms of discrimination against women and children, including violence), but these commitments are yet to be realised. The SDGs constitute a potentially powerful violence prevention agenda (Butchart, 2020), but implementation of activities to achieve the SDGs, in politically and economically uncertain contexts such as Palestine, remains very challenging. The situation is further complicated by over-reliance on humanitarian aid, with most programmes politicised (Raciti, 2006), short term and not necessarily aligned with national strategies, instead focusing on meeting urgent survival needs (Samuels et al., 2018). Also, the principles of the Global Compact on Refugees, which could contribute indirectly to a reduction of violence, have had no impact on violence in Palestine. The nature of the Palestinian-Israeli conflict, the chronicity of the statelessness situation and the exceptional ${ }^{3}$ approach used by the international community in tackling Palestinian refugees' issues, make the realization of the international commitments challenging in the Palestinian situation. Solutions to address violence against adolescents, such as those described here, must take into account the way that the political situation in Palestine shapes the lives of adolescents, their families and their communities and prioritise sustainable approaches that promote adolescent agency and capabilities.

\section{Policy implications}

Overall, our findings underscore the complex and interlinked challenges facing adolescents in Gaza to protect themselves from violence and the critical role of 
political unrest, statelessness, structural and context-specific gendered norms and practices in exposing adolescents (and especially girls) to violence. To contribute to the leave no one behind agenda, there is a need to intensify efforts to address and end violence, both in the community in general and towards children in particular. It is essential to launch a national multisectoral strategy to reduce violence against children and translate this strategy into practical programmes with assigned responsibilities and budget. Palestine's outdated legal framework should be revised to be more age- and gender-equitable.

Violence is unlikely to decrease in Gaza unless policy-makers and actors address its intersecting risk factors in a comprehensive way that considers micro, meso and broader environmental factors, including demanding political resolution of the Palestinian case which will lead to peace, equity, social justice, economic growth and livelihoods, employment, education and women's empowerment. At the more local level, social protection programming, which has largely addressed economic shocks and poverty but ignored challenges related to gender and age, should be scaled up to address children's needs through strengthening child protection and complementary services. A missed opportunity in controlling violence in Gaza is liaising with the existing cadre of social workers who, through the social assistance programme, visit the houses of 75,000 vulnerable beneficiaries. These social workers could play a key role in raising awareness, identifying individuals experiencing violence and abuse and providing support or referring cases of domestic abuse. It is also important to invest in enhancing data collection and monitoring systems. More efforts are needed to ensure harmonisation, coherence and complementarity between social protection actors and between development and humanitarian programmes.

Social norms play a key role in driving violence against children, so it is vital to work towards gradual and progressive social change that promotes more egalitarian age and gender norms. Peer-to-peer approaches that support adolescents and parents to develop positive conflict resolution skills can provide a means to address intra-household violence, although are perhaps difficult to implement at scale. Positive parenting practices provided within existing early childhood development programmes targeting caregivers of preschool children can, however, be scaled up to target parents of older children and adolescents. Caregivers should receive training and awareness on non-violent discipline practices, to replace the prevailing punitive forms of discipline and make them less socially accepted. Involving boys and men in these efforts, and promoting positive masculinities, is also essential.

In schools, there is a need to strengthen protection services, with more investment in child- and adolescent-friendly places and services. School mediation programmes could be scaled up to encourage more involvement by parents, teachers and counsellors, and encourage caregivers and service providers to use non-punitive discipline practices. The Ministry of Education and UNRWA should reinforce regulations that prohibit punishment at schools and also monitor teachers' practices more rigorously. Service providers - particularly teachers and health personnel - 
need specific training on adolescents' needs. Adolescents themselves must also be supported to participate in accountability processes, for example by setting up advisory groups of young people who liaise with staff members who will listen to and advocate for them. School counsellors could also play a significant role in combating violence, not only in schools but also in other public places and in the home.

Our analysis confirms that other than treating their physical injuries, adolescents who have experienced violence have limited support available. Using different communication channels, particularly social and mass media, it is essential to increase awareness among adolescents about their rights and the available support services, as well as extending these services to meet people's needs. Online forums for reporting violence and seeking assistance could also be helpful, provided that there is adequate safeguarding, including measures to ensure confidentiality, to help protect young people who access support in this way.

\section{Notes}

1 SDG target 5.2: Eliminate all forms of violence against women and girls; SDG target 5.3: Eliminate all harmful practices, such as child, early and forced marriage and female genital mutilation; SDG target 16.1: Significantly reduce all forms of violence and related death rates everywhere; and SDG target 16.2: End abuse, exploitation, trafficking and all forms of violence against children.

2 SDG 1: End poverty; SDG 3: Good health; SDG 4: Quality education; SDG 5: Gender equity; SDG 10: Reduced inequalities; SDG 11: Sustainable cities and communities; SDG 16: Peace and justice.

3 UNHCR has a mandate to provide international protection and search for durable solutions for refugees worldwide, but in the case of Palestinian refugees these protections only apply if other agencies - primarily UNRWA - are unable to do so, and for complex political and economic reasons the commitment to a permanent solution has yet to be demonstrated.

\section{References}

Abu Hamad, B., Gercama, I., Jones, N., and Abu Hamra, E. (2017) 'No one told me about that': exploring adolescent access to health services and information in Gaza. London: Gender and Adolescence: Global Evidence. Available at: www.gage.odi.org/publications

Abu Hamad, B., Jones, N., Al Bayoumi, N., and Samuels, F. (2015) Mental health and psychosocial support service provision for adolescent girls in post-conflict settings: the case of the Gaza Strip. London: Overseas Development Institute.

Abu Hamad, B., Jones, N., and Pereznieto, P. (2014) Tackling children's economic and psychosocial vulnerabilities synergistically: how well is the Palestinian National Cash Transfer Programme serving Gazan children? Children and Youth Services Review 47(2): 121-135.

Al-Krenawi, A. (2012) The impact of political violence on psychosocial functioning of individuals and families: the case of Palestinian adolescents. Child and Adolescent Mental Health 17(1): 14-22.

Ansell, N. (2009) Childhood and the politics of scale: descaling children's geographies? Progress in Human Geography 33(2): 190-209. 
Butchart, A. (2020) The Sustainable Development Goals (SDG) and violence prevention: how do they connect? Geneva: World Health Organization.

Cahill, C., and Hart, R.A. (2006) Pushing the boundaries: critical international perspectives on child and youth participation - series introduction. Children, Youth and Environments 16(2): I-III.

GAGE consortium. (2019) Gender and adolescence: why understanding adolescent capabilities, change strategies and contexts matters. Second edition. London: Gender and Adolescence: Global Evidence.

Hart, J. (2010) Dislocated masculinity: adolescence and the Palestinian nation-in-exile. In: Hart, J. (Ed.), Years of conflict: adolescence, political violence and displacement. New York: Berghahn Books.

Human Rights Council. (2017) Report of the Special Rapporteur on violence against women, its causes and consequences, on her mission to the Occupied Palestinian Territory/State of Palestine. Geneva:The Office of the High Commissioner for Human Rights (UN Human Rights). Available at: www.ohchr.org/en/issues/women/srwomen/pages/srwomenindex.aspx

Jewkes, R. (2002) Intimate partner violence: causes and prevention. The Lancet 359(9315): 1423-1429.

Jones, N., Baird, S., Presler-Marshall, E., Małachowska, A., Kilburn, K., Abu Hamad, B., Essaid, A., Amaireh, W., Sajdi, J., Banioweda, K., Alabbadi, T., Alheiwidi, S., Ashareef, Q., Altal, S., Kharabsheh, W., Abu Taleb, H., Abu Azzam, M., and Abu Hammad, B. (2019) Adolescent well-being in Jordan: exploring gendered capabilities, contexts and change strategies. A synthesis report on GAGE Jordan baseline findings. London: Gender and Adolescence: Global Evidence.

Jones, N., Gercama, I., Presler-Marshall, E., and Abu Hamad, B. (2017) Adolescent perspectives on services and programmes in conflict-affected contexts: participatory research toolkit. London: Gender and Adolescence: Global Evidence. Available at: www.gage.odi.org/publications/ participatory-toolkit

Ministry of Health. (2020) Annual health status report. Gaza: Ministry of Health.

Ministry of Women's Affairs. (2011) National strategy to combat violence against women 20112019. Ramallah: Ministry of Women's Affairs National Committee to Combat Violence Against Women.

Müller, C., and Tranchant, J-P. (2017) Tackling violence against women and girls in Gaza. IIED Working Paper. London: International Institute for Environment and Development.

Palestinian Central Bureau of Statistics (PCBS). (2011) Main findings of violence survey in the Palestinian society. Ramallah: PCBS. Available at: www.pcbs.gov.ps/Portals/_pcbs/ PressRelease/el3onf2011_E.pdf

PCBS. (2015) Palestinian multiple indicator cluster survey 2014: final report. Ramallah: PCBS.

PCBS. (2016) Palestinian youth survey, 2015: main findings. Ramallah: PCBS.

PCBS. (2018) Preliminary results of the Population, Housing and Establishments Census, 2017. Ramallah: PCBS.

PCBS. (2019a) Palestinian labour force survey: annual report. Ramallah: PCBS.

PCBS. (2019b) Preliminary results of the violence survey in Palestinian society 2019. Ramallah: PCBS.

Pereznieto, P., Jones, N., Abu Hamad, B., and Shaheen, N. (2014) Effects of the Palestinian National Cash Transfer Programme on children and adolescents: a mixed methods analysis. Jerusalem and London: UNICEF and Overseas Development Institute.

Raciti, I. (2006) The political dimension of humanitarian action: rethinking the humanitarian space. Yearbook on Humanitarian Action and Human Rights. Spain: Universidad de Deusto.

Samuels, F., Jones, N., and Abu Hamad, B. (2017) Psychosocial support for adolescent girls in post-conflict settings: beyond a health systems approach. Health Policy and Planning 32(suppl 5):V40-V51. 
Samuels, F., Jones, N., and Abu Hamad, B. (2018) Psychosocial support for adolescent girls in post-conflict settings: a social and gendered norms approach. Humanitarian Exchange Number 72, 26-29 July 2018.

Sen, A. (1984) Commodities and capabilities. Oxford: Oxford University Press.

Sen, A. (2004) Capabilities, lists, and public reason: continuing the conversation. Feminist Economics 10(3): 77-80.

Tefferi, H. (2010) Reconstructing adolescence after displacement: experience from eastern Africa. In: Hart, J. (Ed.), Years of conflict: adolescence, political violence and displacement. New York: Berghahn Books.

Thabet, A., Tischler, V., and Vostanis, P. (2004) Maltreatment and coping strategies among male adolescents living in the Gaza Strip. Child Abuse \& Neglect 28(1): 77-91.

The Palestinian Initiative for the Promotion of Global Dialogue and Democracy (MIFTAH), Independent Commission for Human Rights (ICHR) and United Nations Population Fund (UNFPA). (2015) Country assessment towards monitoring and reporting sexual and reproductive health and rights [SRHR] in Palestine. Ramallah: MIFTAH. Available at: www. miftah.org/Publications/Books/Country_Assessment_Book2015.pdf

United Nations. (2017) Gaza ten years later: United Nations Country Team in the occupied Palestinian territory. Palestine: United Nations.

United Nations Children's Fund (UNICEF). (2014a) Ending child marriage: progress and prospects. New York: UNICEF.

UNICEF. (2014b) Hidden in plain sight: a statistical analysis of violence against children. New York: UNICEF. Available at: www.unicef.org/publications/index_74865.html

UNICEF. (2016) UNICEF global databases. New York: UNICEF. Available at: https://data. unicef.org/topic/child-protection/overview

UNICEF. (2017) Preventing and responding to violence against children and adolescents: theory of change. New York: UNICEF.

UNICEF. (2018) Children in the State of Palestine. Palestine: UNICEF.

United Nations Development Programme (UNDP). (2018) What does it means to leave no one behind? A UNDP discussion paper and framework for implementation. New York: UNDP.

United Nations Educational, Scientific and Cultural Organization (UNESCO). (2017) School violence and bullying: global status report. Paris: UNESCO. Available at: http://unesdoc. unesco.org/images/0024/002469/246970e.pdf

United Nations High Commissioner for Refugees (UNHCR). (2019) The Global Compact on Refugees: indicator framework. Geneva: UNHCR.

Women's Refugee Commission (WRC). (2016) A girl no more: the changing norms of child marriage in conflict. New York: WRC.

World Bank. (2015) Gaza economy on the verge of collapse, youth unemployment highest in the region at 60 percent. Press Release, 21 May 2015. Available at: www.worldbank.org/ en/news/press-release/2015/05/21/gaza-economy-on-the-verge-of-collapse

World Bank. (2019) Data: selected countries and economies. World Bank Group. Available at: https://data.worldbank.org/indicator/SP.ADO.TFRT?end=2017\&locations $=$ SY\&sta $\mathrm{rt}=2010$

World Health Organization (WHO). (2002) World report on violence and health. Geneva:WHO.

WHO. (2013) Global and regional estimates of violence against women: prevalence and health effects of intimate partner violence and non-partner sexual violence. Geneva: WHO. 